\title{
Upward Flame Spread: The Width Effect
}

\author{
KUANG-CHUNG TSAI and FU-SEN WAN \\ Department of Safety, Health and Environmental Engineering \\ National Kaohsiung First University of Science and Technology \\ 2 Juoyue Road \\ Nantzu, Kaohsiung 811, Taiwan
}

\begin{abstract}
Previous work has demonstrated upward flame spread on vertical surfaces to be one of the most hazardous fire scenarios. To assess the risk of this scenario, several models have been developed to predict the flame spread rate, relying on empirical correlations of flame height and heat feedback to unburned surface ahead of pyrolysis region. However, the width effect was not regarded particularly in those models but to influence flame thickness, causing the variation of radiation. Therefore, experiment has been designed to access the width effect. Samples used were 6 and $20 \mathrm{~mm}$ thick clear PMMA with height of $1000 \mathrm{~mm}$ and widths of $100,300,500,700$ and $900 \mathrm{~mm}$. Our data showed that the width effect was significant for samples less than $300 \mathrm{~mm}$ wide and not significant for 300 to $900 \mathrm{~mm}$ wide samples. In addition, the width effect was slight in total heat flux distribution and not obvious in flame height correlation. As to the radiant heat flux distribution, our measurements were much lower than recognized in previous studies.
\end{abstract}

KEYWORDS: upward flame spread, width effect, flame height, heat feedback

\section{NOMENCLATURE}

$K \quad$ effective emission coefficient $\left(\mathrm{m}^{-1}\right)$

$L \quad$ mean beam length $(\mathrm{m})$

$\dot{Q}^{\prime} \quad$ heat release rate per unit width $(\mathrm{kW} / \mathrm{m})$

$\dot{Q}_{\text {rad }} \quad$ radiant heat flux $\left(\mathrm{kW} / \mathrm{m}^{2}\right)$

$\dot{q}^{\prime \prime} \quad$ total heat flux $\left(\mathrm{kW} / \mathrm{m}^{2}\right)$

$T$ temperature $(\mathrm{K})$

$X \quad$ vertical distance from the bottom of wall $(\mathrm{m})$

$X_{b} \quad$ burnout front height $(\mathrm{m})$

$X_{f} \quad$ flame height $(\mathrm{m})$

$X_{p} \quad$ pyrolysis height $(\mathrm{m})$

$\varepsilon \quad$ emissivity (-)

$\sigma \quad$ Stefan-Boltzmann constant $\left(5.67 \times 10^{-8} \mathrm{~W} / \mathrm{m}^{2} \cdot \mathrm{K}^{4}\right)$

\section{INTRODUCTION}

Previous work has demonstrated upward flame spread on vertical surfaces to be one of the most hazardous fire scenarios due to concurrent direction of flame propagation and air flow. The process is illustrated in Fig. 1 . The surface in the region $\left(X_{f}-X_{p}\right)$ is heated progressively and when the surface achieves its ignition temperature, the flame propagates. Clearly, flame height and heat transfer in the region $\left(X_{f}-X_{p}\right)$ play crucial roles. 
To assess the risk, several models [1-12] have been developed. Most of these models relied on empirical correlations of flame height and heat feedback to unburned surface ahead of pyrolysis region and the effect of the width of burning area is not considered in those correlations. Their predictions have been compared with experiments and reasonable agreements were showed.

However, the width of burning area is regarded to influence flame thickness [13], causing the variation of radiation. (The "thickness" is orthogonal to the PMMA surface.) This has been shown to affect the flame height correlations [14] and heat flux to the unburned surface [13]. In addition, the previous models (see Table 1) used different heat flux representatives in their modeling work. One interesting point is that the representative heat fluxes used were larger while the burning areas in their experiments were wider (see Fig. 2) besides one study which underestimated flame spread rate [8]. Therefore, the existence of width effect was implies. In our study, the width effect is focused on furthermore and experiments have been designed to access its effect.

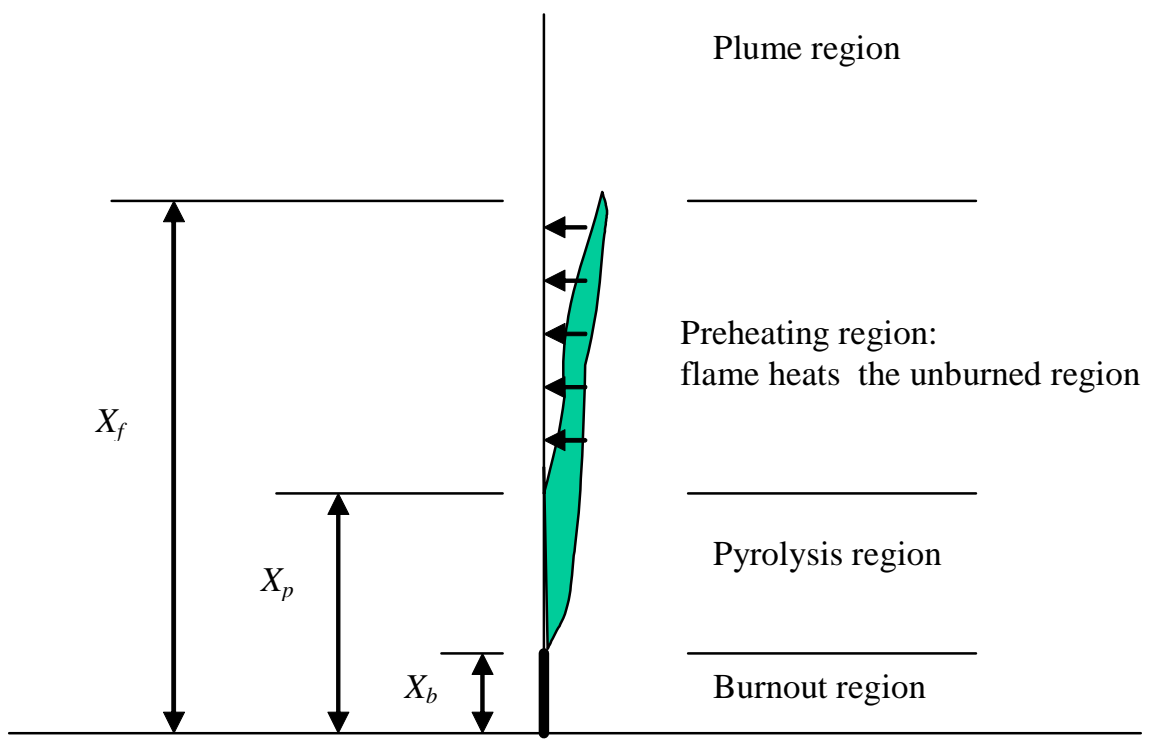

Fig. 1. Upward flame spreading. 
Table 1. The heat flux to unburned surface and the width of burning area in experiments in some upward flame spread models.

\begin{tabular}{|c|c|c|}
\hline $\begin{array}{l}\text { Modeling work of upward } \\
\text { flame spread }\end{array}$ & $\begin{array}{l}\text { The heat flux to unburned } \\
\text { surface used in modeling } \\
\text { work }\left(\mathrm{kW} / \mathrm{m}^{2}\right)\end{array}$ & $\begin{array}{l}\text { The width of burning } \\
\text { area in experiments } \\
\text { (m) }\end{array}$ \\
\hline Saito et al. [1] & 25 & 0.3 \\
\hline Mowrer and Williamson [2] & 30 & Nil \\
\hline Delichatsios et al.[3] & 30 & 0.41 \\
\hline $\begin{array}{l}\text { Delichatsios and } \\
\text { Delichatsios [4] }\end{array}$ & 25 & 0.2 \\
\hline Delichatsios and Chen [5] & 25 & Nil \\
\hline Grant and Drysdale [6] & 20 & Nil \\
\hline Anderson et al. [7] & 35 & 0.6 \\
\hline Kokkala et al. [8] & 25 & 1.2 \\
\hline Qian and Saito [9] & 25 & Nil \\
\hline Quintiere and Lee [10] & 25 & Nil \\
\hline Tsai and Drysdale $[11,12]$ & 15 & 0.08 \\
\hline
\end{tabular}

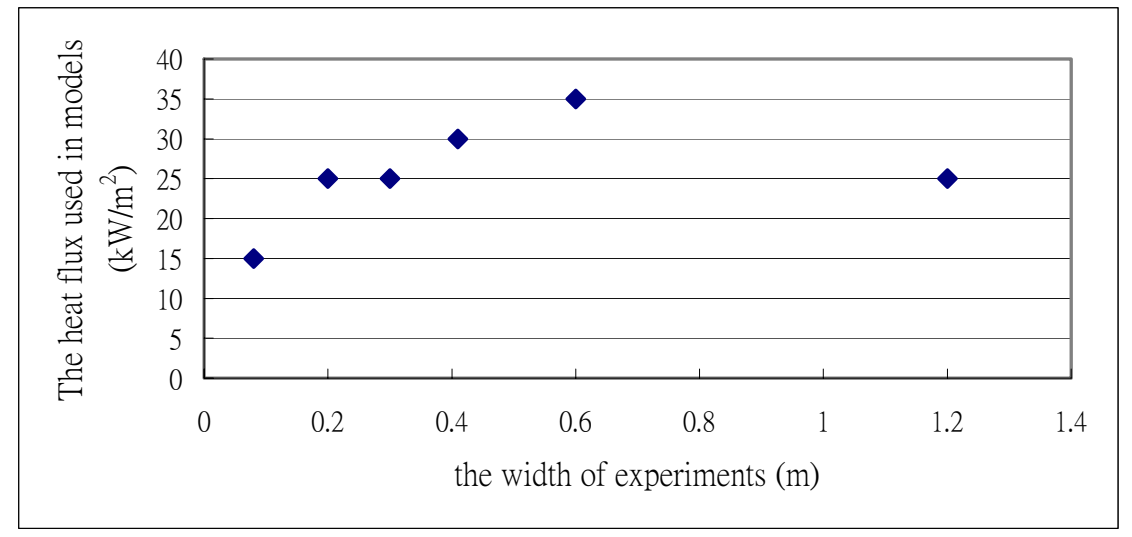

Fig. 2. The relationship of heat flux used in models and widths of burning area in experiments.

\section{EXPERIMENTAL}

A schematic of the experimental set-up is shown in Fig. 3. The samples used were 6 and $20 \mathrm{~mm}$ thick clear PMMA, $1000 \mathrm{~mm}$ tall and with width of 100, 300, 500, 700, and $900 \mathrm{~mm}$. The samples were held against a $3 \mathrm{~mm}$ thick steel plates to prevent flame spreading up the back of the sample, distortion and slumping. Two $50 \mathrm{~mm}$ wide sidewalls made of marinite were used to produce uniform flame height. A hand-held butane-fueled 
blowtorch was used to ignite the bottom $100 \mathrm{~mm}$ of the sample and removed out after ignition. One Gargon-gage total heat flux meter was set up at position of $850 \mathrm{~mm}$ height along the central line of the sample and one Schmidt-Boelter radiant heat flux meter $8 \mathrm{~mm}$ above the total heat flux meter. In addition, the visual flame thickness at the top of the samples was recorded by eye for further radiation estimation. The height of flames was recorded by a camcorder and the rate of upward flame spread was determined by analyzing infra-red video recordings of each experiment. The accompanying software allowed the pyrolysis front to be tracked as the $350^{\circ} \mathrm{C}$ contour as it advanced upwards. This experimental arrangement measured flame height, total/radiant heat transfer and flame spread rate simultaneously.

\section{RESULTS AND DISCUSSION}

The experiments were designed to provide data on the early stages of fire growth on a vertical surface. Figure 4 shows typical measurements of the pyrolysis front and flame height on a $100 \mathrm{~mm}$ wide and $1000 \mathrm{~mm}$ high PMMA sample.

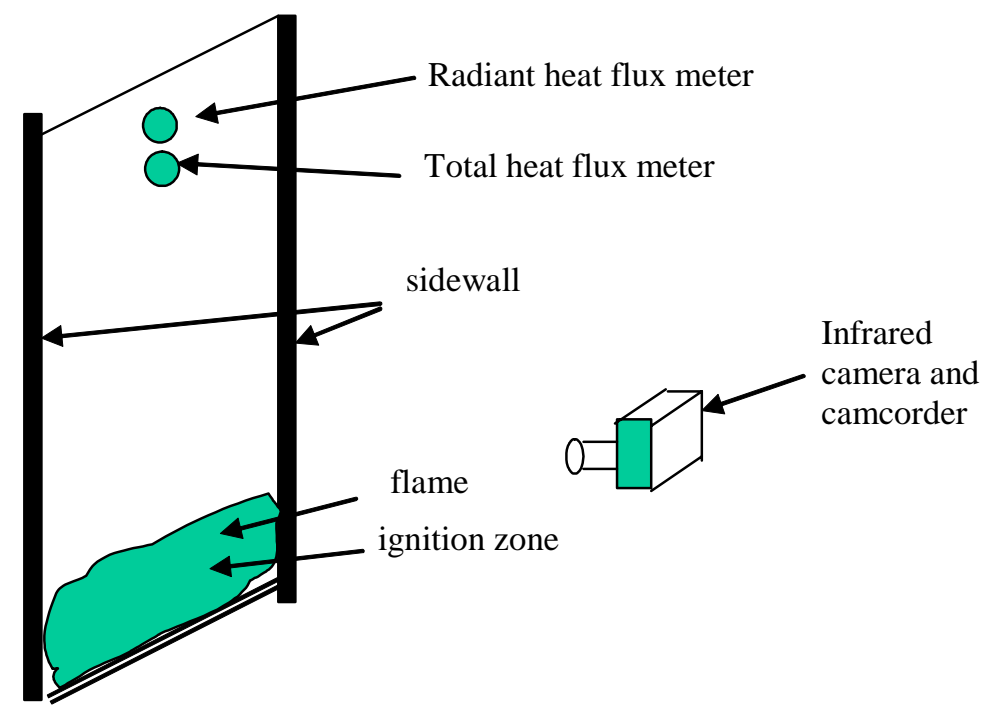

Fig. 3. The experimental rig.

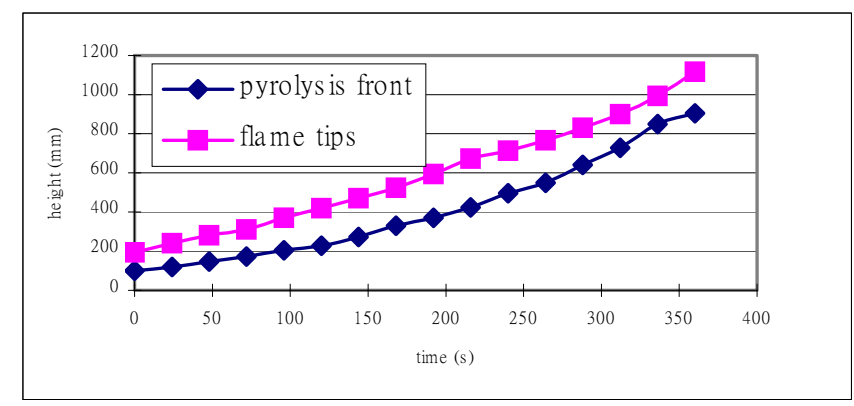

Fig. 4. A typical flame height and pyrolysis front measurement on a 100 mm wide PMMA sample as a function of time. 


\section{Flame Height Correlation}

Figure 5 and Fig. 6 show the flame height measurements (average of 3 tests) against pyrolysis height of these 100, 300, 500, 700 and $900 \mathrm{~mm}$ wide samples. The results shown in Fig. 5 were for 6 mm thick samples while in Fig. 6 were 20 mm thick samples. These measurements were compared with the correlation produced from data of Hasemi [15] and Tu and Quintiere [16], giving $X_{f}=0.032 \dot{Q}^{\prime 0.76}$. Very good agreement was shown. In addition, it can be seen that the width effect was not obvious.

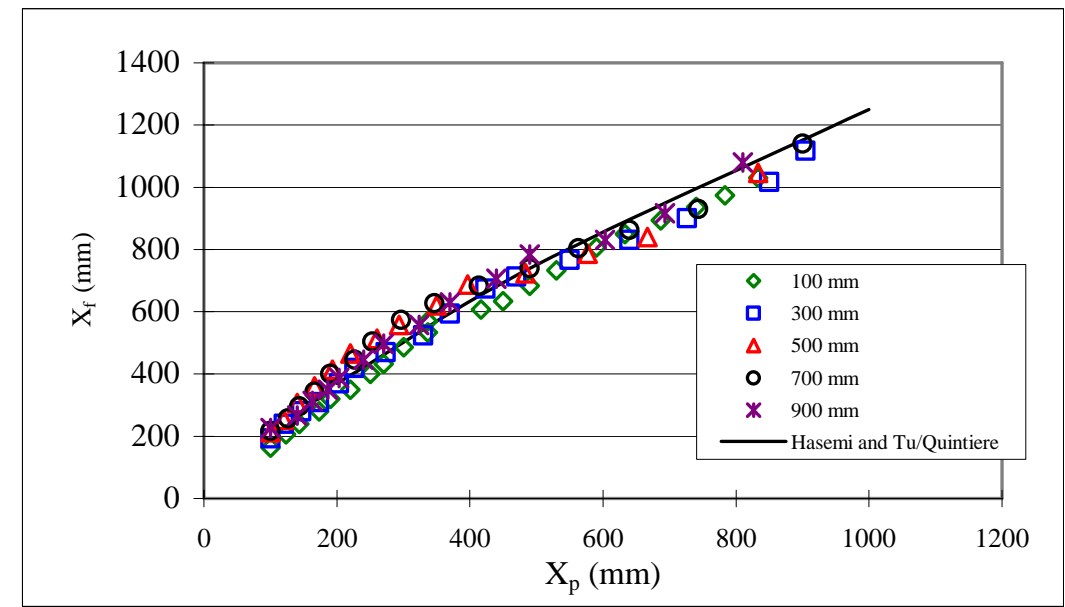

Fig. 5. The flame height correlation (against pyrolysis height) of 100, 300, 500, 700, $900 \mathrm{~mm}$ wide and $6 \mathrm{~mm}$ thick samples.

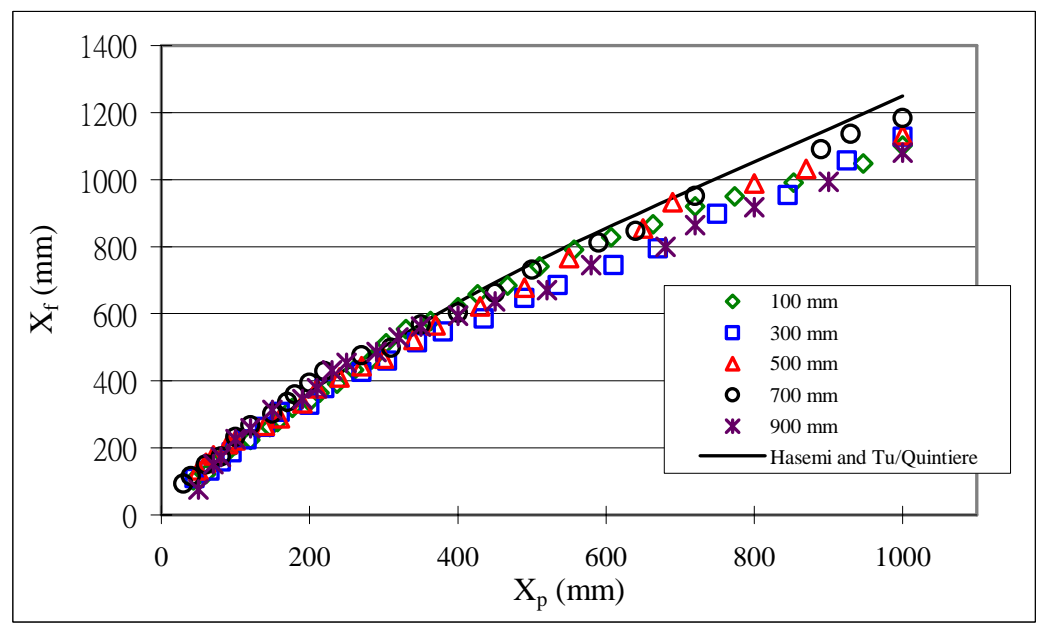

Fig. 6. The flame height correlation (against pyrolysis height) of 100, 300, 500, 700, $900 \mathrm{~mm}$ wide and $20 \mathrm{~mm}$ thick samples. 


\section{Heat Flux Correlation}

Figure 7 and Fig. 8 present the total and radiant heat flux distributions (average of 3 tests) of the spreading PMMA wall fires plotted as a function of height $(X)$ normalised against the flame height $\left(X_{f}\right)$. Only the data for $20 \mathrm{~mm}$ thick and 100, 300, 500 and $700 \mathrm{~mm}$ wide samples were showed here. For $6 \mathrm{~mm}$ thick and $900 \mathrm{~mm}$ wide samples, the thermal expansion of mild backing steel during the flame spreading especially for wider flames occurred and caused deformation which led to a change of positions of heat flux meters and influenced heat flux measurements.

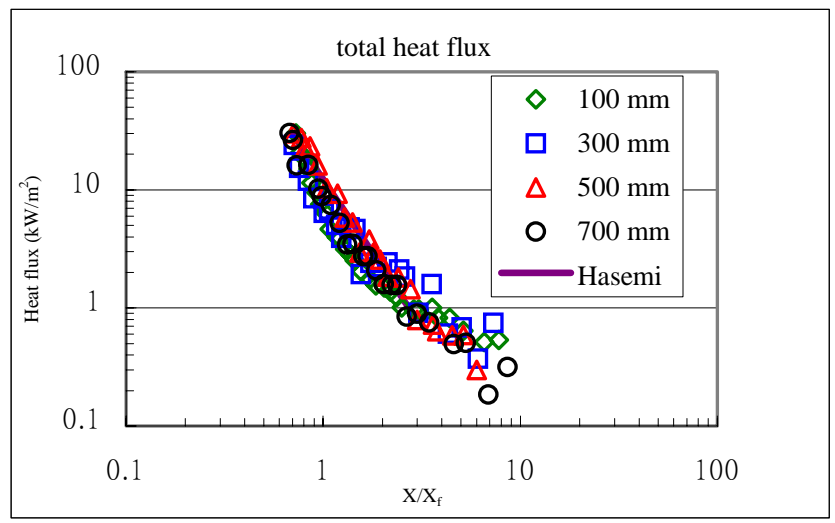

Fig. 7. The total heat flux distributions of the spreading PMMA wall fires plotted as a function of height $(\mathrm{X})$ normalised against the flame height.

The samples were $20 \mathrm{~mm}$ thick.

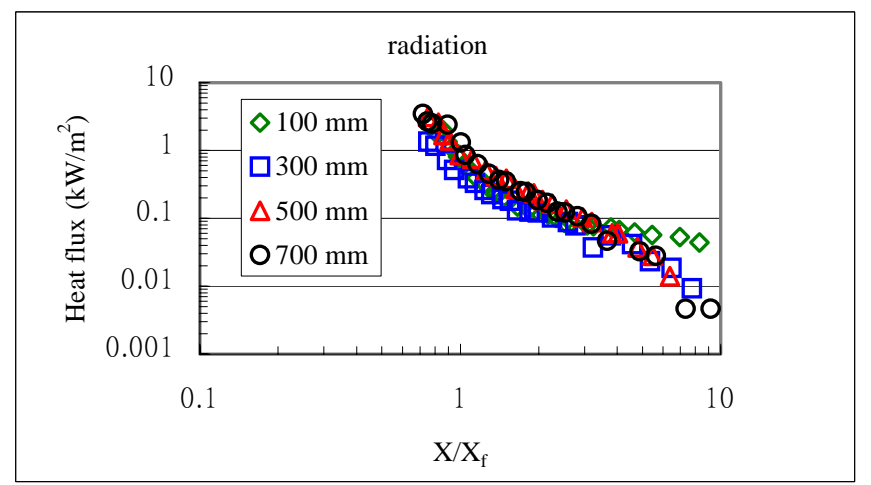

Fig. 8. The radiation distributions of the spreading PMMA wall fires plotted as a function of height $(\mathrm{X})$ normalised against the flame height.

The samples were $20 \mathrm{~mm}$ thick.

The total and radiant heat fluxes for PMMA samples of different widths while flame tips reached the heat flux meters and pyrolysis fronts did were listed in Table 2. The total heat fluxes were between $8-10 \mathrm{~kW} / \mathrm{m}^{2}$ and $25-30 \mathrm{~kW} / \mathrm{m}^{2}$. This indicates the total heat flux distribution of the preheating region (see Fig. 1). Hasemi's correlation [15], giving 
$\dot{q}^{\prime \prime}=12.3\left(X / X_{f}\right)^{-2.5}$ (for $X / X_{f}>0.7$ ), was additionally put in Fig. 7 for comparison. Very good agreement was shown. Furthermore, it can generally be seen that for wider flames, the total heat fluxes were higher. However, the effect was not significant. As to the radiant heat flux, the measurements were about $0.3-3.5 \mathrm{~kW} / \mathrm{m}^{2}$. These values were very low and the width effect was not obvious.

Table 2. The total and radiant heat fluxes for PMMA samples of different widths while flame tips reached the heat flux meters and pyrolysis fronts did.

\begin{tabular}{|c|c|c|c|c|}
\hline \multirow{2}{*}{$\begin{array}{c}\text { Width } \\
\text { of } \\
\text { sample } \\
\text { (mm) }\end{array}$} & \multicolumn{2}{|c|}{ Total heat flux } & \multicolumn{2}{|c|}{ Radiant heat flux } \\
\hline & $\begin{array}{c}\text { flame tips } \\
\text { reached the heat } \\
\text { flux meter } \\
\left(\mathrm{kW} / \mathrm{m}^{2}\right)\end{array}$ & $\begin{array}{l}\text { pyrolysis fronts } \\
\text { reached the heat } \\
\text { flux meter } \\
\left(\mathrm{kW} / \mathrm{m}^{2}\right)\end{array}$ & $\begin{array}{c}\text { flame tips } \\
\text { reached the heat } \\
\text { flux meter } \\
\left(\mathrm{kW} / \mathrm{m}^{2}\right)\end{array}$ & $\begin{array}{c}\text { pyrolysis } \\
\text { fronts reached } \\
\text { the heat flux } \\
\text { meter }\left(\mathrm{kW} / \mathrm{m}^{2}\right)\end{array}$ \\
\hline 100 & 9.49 & 23.58 & 0.61 & 2.31 \\
\hline 300 & 8.45 & 23.95 & 0.38 & 1.35 \\
\hline 500 & 10.28 & 30.04 & 0.85 & 3.15 \\
\hline 700 & 10.21 & 30.21 & 1.30 & 3.47 \\
\hline
\end{tabular}

\section{Radiation at Pyrolysis Front Estimated by Visual Flame Thickness}

The radition measured in this study was very low compared with data from previous studies [13] noticing that radiation plays a primary role in wall fires. Therefore, the radiation measurements were checked with estimations by visual flame thickness. Although this estimation method is of approximation, it should give some information. The radiation from luminous flames can be calculated by equation 1 .

$\dot{Q}_{\text {rad }}=\varepsilon \sigma T^{4}$

where $\sigma$ is the Stefan-Boltzmann constant $\left(5.67 \times 10^{-8} \mathrm{~W} / \mathrm{m}^{2} \mathrm{~K}^{4}\right), \varepsilon$ is the emissivity and $T$ is the temperature (K). The emissivity can be estimated by Kirchhoff's law (equation 2)

$\varepsilon=1-\exp (-K L)$

where $K$ is an effective emission coefficient and $L$ is the flame thickness (or mean beam length). The value of $K$ for PMMA is taken to be 1.3 [13], and flame temperature to be $850^{\circ} \mathrm{C}(1125 \mathrm{~K})$. The flame thickness at pyrolysis front for samples of different widths is presented in Table 3. The radiation is calculated and shown in Table 3 to be among c. 5 to $9 \mathrm{~kW} / \mathrm{m}^{2}$. These values were higher than our measurements (Table 2), less than the experimental result by Zhang et al. [17] to be c. $12 \mathrm{~kW} / \mathrm{m}^{2}$ and much less than the recognised radiation of wall fires to be $25 \sim 30 \mathrm{~kW} / \mathrm{m}^{2}$ (see Table 1). Inconsistency exists. 


\section{Flame Spread Rate}

Figures 9 and 10 show the flame spread rates (average of 3 tests) of the wall fires. Figure 9 is for $6 \mathrm{~mm}$ thick samples while Fig. 10 for $20 \mathrm{~mm}$ thick samples. It can be seen that the width effect existed. For both sets of experiments, the difference is not significant among the flames of 300, 500, 700 and $900 \mathrm{~mm}$ wide and the $100 \mathrm{~mm}$ wide flames spread much slower than those cases.

Table 3. The flame thickness and calculated radiation to the unburned surface of samples measured while the pyrolysis front reached the position of heat flux meters.

\begin{tabular}{|c|c|c|}
\hline $\begin{array}{l}\text { Width of flame } \\
\text { (mm) }\end{array}$ & $\begin{array}{l}\text { Thickness of flame } \\
\text { (mm) }\end{array}$ & $\begin{array}{c}\text { Radiation } \\
\left(\mathrm{kW} / \mathrm{m}^{2}\right)\end{array}$ \\
\hline 100 & 45 & 5.12 \\
\hline 300 & 50 & 5.68 \\
\hline 500 & 80 & 8.91 \\
\hline 700 & 80 & 8.91 \\
\hline 900 & 80 & 8.91 \\
\hline
\end{tabular}

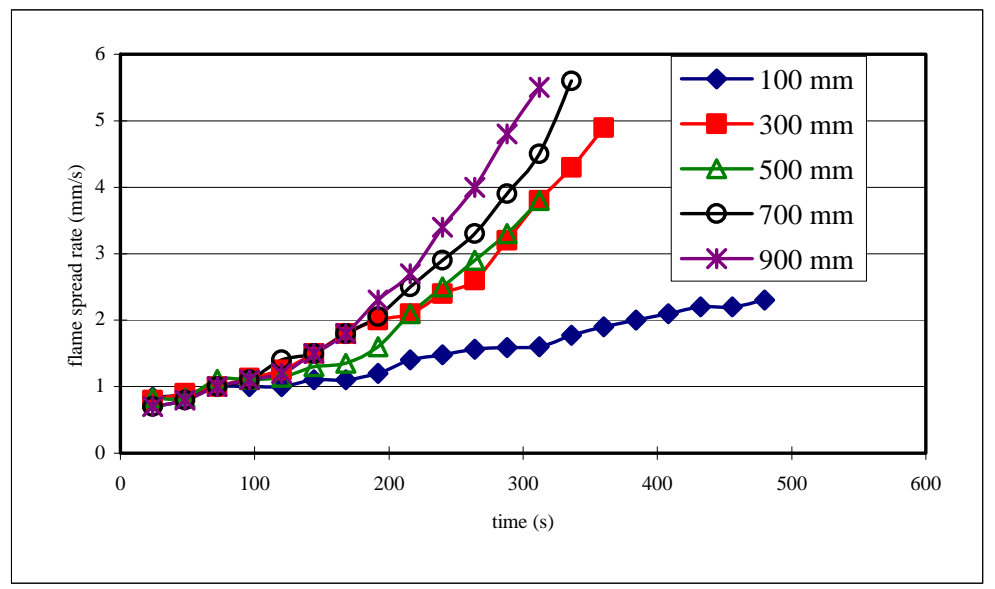

Fig. 9. The flame spread rates of the wall fires. The samples were $6 \mathrm{~mm}$ thick. 


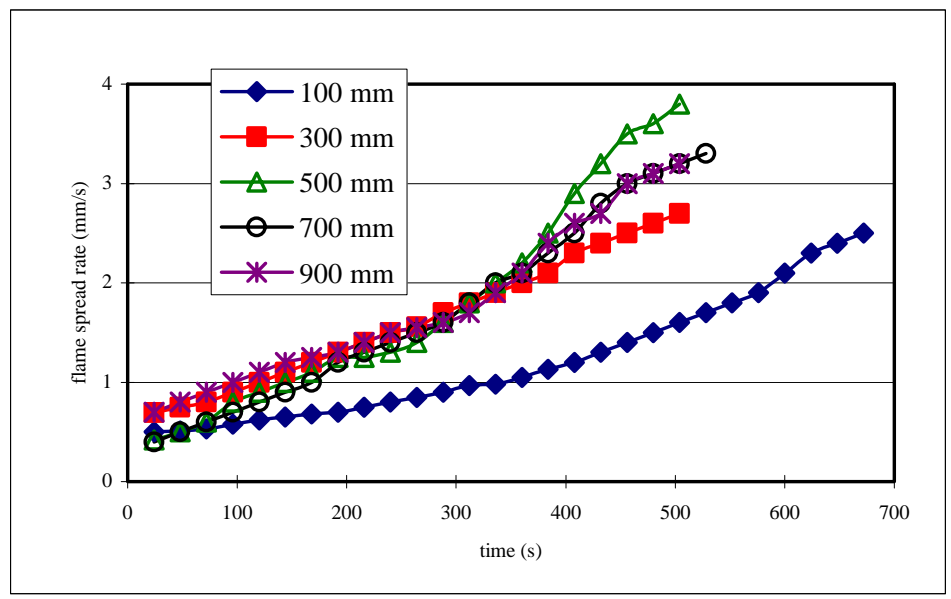

Fig. 10. The flame spread rates of the wall fires. The samples were $20 \mathrm{~mm}$ thick.

\section{Sample Thickness Effect}

The samples used were 6 and $20 \mathrm{~mm}$ thick PMMA. Comparing the data for samples of different thicknesses, the flame height correlation and heat flux distribution did not varied with thickness. However, the flames spreading on thicker samples propagated slower. This is consistent with the studies reported by Drysdale [13].

\section{Further Modeling Work}

In upward flame spread models, it is important to use as input data the best available representations of flame height and heat transfer to the preheating region. Previous models did not consider the width effect. Therefore, their flame height correlation and heat flux distribution were identical. However, from our data, the width effect was significant in flame spread rate, which clearly shows that one-dimensional simplification is not proper for samples wider than $300 \mathrm{~mm}$.

\section{CONCLUSION}

Experiments were designed to study the width effect in upward flame spread. Our data showed that the width effect does exist for samples less than $300 \mathrm{~mm}$ wide and not significant from 300 to $900 \mathrm{~mm}$ wide. In addition, the width effect is slight in total heat flux distribution and not obvious in flame height correlation. As to the radiant heat flux distribution, our measurements were much lower than recognized in previous studies.

\section{ACKNOWLEDGUMENTS}

The authors wish to thank Nation Science Council for financial support (project number: NSC 92-2212-E-327-003) and Mr. Zhong-Gin Chen and Shin-Hon Chen for their assistance to carry out experimental data. 


\section{REFERENCE}

[1] Saito, K., Quintiere, J.G., and Williams, F.A., "Upward Turbulent Flame Spread," Fire Safety Science- Proceedings of the First International Symposium, pp. 75-86, 1985.

[2] Mowrer, F.W., and Williamson, R.B., "Flame Spread Evaluation for thin interior finish materials," Fire Safety Science- Proceedings of the Third International Symposium, pp. 689-698, 1991.

[3] Delichatsios, M.M., Mathews, M.K., and Delichatsios, M.A., "An Upward Fire Spread and Growth Simulation," Fire Safety Science- Proceedings of the Third International Symposium, pp. 207-216, 1991.

[4] Delichatsios, M.A., and Delichatsios, M.M., "Upward Flame Spread and Critical Conditions for PE/PVC Cables in a Tray Configuration," Fire Safety ScienceProceedings of the Fourth International Symposium, pp. 433-444, 1995.

[5] Delichatsios, M.A., and Chen, Y., "Flame Spread on Charring Materials: Numerical Predictions and Critical Conditions," Fire Safety ScienceProceedings of the Fourth International Symposium, pp. 457-468, 1995.

[6] Grant, G., and Drysdale, D., "Numerical Modelling of Early Flame Spread in Warehouse Fires,” Fire Safety Journal, 24, pp. 247-278, 1995.

[7] Anderson, M., and McKeever, C., "An Experimental Study of Upward Flame Spread on Cellulosic Materials," Proceedings of the Seventh International Fire Safety and Engineering Conference INTERFLAM'96, pp. 169-178, 1996.

[8] Kokkala, M., Baroudi, D., and Parker, W.J., "Upward Flame Spread on Wooden Surface Products: Experiments and Numerical Modelling," Fire Safety ScienceProceedings of the Fifth International Symposium, pp. 309-320, 1997.

[9] Qian, C., and Saito, K., "An Empirical Model for Upward Flame Spread Over Vertical Flat and Corner Walls," Fire Safety Science- Proceedings of the Fifth International Symposium, pp. 285-296, 1997.

[10] Quintiere, J.G., and Lee, C.H., "Ignitor and Thickness Effects on Upward Flame Spread,” Fire Technology, 34, No.1, pp.18-38, 1998.

[11] Tsai, K.C., and Drysdale, D., "Flame Height Correlation and Upward flame Spread Modelling,” Fire and Materials, 26, pp. 279-287, 2002.

[12] Tsai, K.C., and Drysdale, D., Using Cone Calorimeter Data for the Prediction of Fire Hazard,” Fire Safety Journal, 37, pp. 697-706, 2002.

[13] Drysdale, D., “An Introduction to Fire Dynamics,” Second Edition, John Wiley and Sons, 1998.

[14] Tsai, K.C., and Drysdale, D., "Upward Flame Spread: Heat Transfer to the Unburned Surface,” The $7^{\text {th }}$ Symposium of IAFSS, 2001.

[15] Hasemi, Y., "Experimental Wall Flame Heat Transfer Correlations for the Analysis of Upward Flame Spread," Fire Science and Technology, 4, pp.75-90, 1984. 
[16] Tu, K.M., and Quintiere, J.G., "Wall Flame Heights with External Radiation," Fire Technology, 27, pp.195-203, 1991.

[17] Zhang, J., Ferraris, S., Dembele, S., Wen, J.X., Goransson, U., and Holmstedt, G., "Numerical and Experimental Investigation of Flame Spread Over a PMMA Surface,” InterFlam 2004, pp. 1221-1232, 2004. 
